\title{
Female physicist doctoral experiences
}

\author{
Katherine P. Dabney* \\ Department of Teaching and Learning, School of Education, Virginia Commonwealth University, Richmond, Virginia 23284, USA \\ Robert H. Tai \\ Curriculum, Instruction, and Special Education, Curry School of Education, University of Virginia, \\ Charlottesville, Virginia 22904, USA \\ (Received 15 November 2012; published 10 April 2013)
}

\begin{abstract}
The underrepresentation of women in physics doctorate programs and in tenured academic positions indicates a need to evaluate what may influence their career choice and persistence. This qualitative paper examines eleven females in physics doctoral programs and professional science positions in order to provide a more thorough understanding of why and how women make career choices based on aspects both inside and outside of school and their subsequent interaction. Results indicate that female physicists experience conflict in achieving balance within their graduate school experiences and personal lives and that this then influences their view of their future careers and possible career choices. Female physicists report both early and longterm support outside of school by family, and later departmental support, as being essential to their persistence within the field. A greater focus on informal and out-of-school science activities for females, especially those that involve family members, early in life may help influence their entrance into a physics career later in life. Departmental support, through advisers, mentors, peers, and women's support groups, with a focus on work-life balance can help females to complete graduate school and persist into an academic career.
\end{abstract}

DOI: 10.1103/PhysRevSTPER.9.010115

PACS numbers: 01.40.- d

The National Academy of Sciences (National Academy of Science, the National Academy of Engineering, and the Institute of Medicine) have emphasized a focus on achieving success in advanced science, technology, engineering, and mathematics (STEM) education due to the narrowing of the STEM workforce and its limited representation of females [1,2]. Recommendations include enlarging the pool of students pursuing degrees and careers and preventing attrition of specialists in STEM fields.

One method of promoting advanced science education, student interest, and career choice has been the use of outreach programs to provide guidance and support to special interest groups, such as female physical scientists, both academically and professionally within the field [1]. Unfortunately, without a better understanding of what motivates and encourages these female graduate students and professionals in science, support cannot be adequately provided in order to encourage individuals to persist within these fields [3]. And despite long-standing educational efforts, more research is necessary that looks at factors that support women, especially in underrepresented groups such as female physicists [4].

Little research has been done in relation to females in physics advanced education, employment, and career

\footnotetext{
*Corresponding author. kdabney@vcu.ed
}

Published by the American Physical Society under the terms of the Creative Commons Attribution 3.0 License. Further distribution of this work must maintain attribution to the author(s) and the published article's title, journal citation, and DOI. satisfaction and success [5-8]. What we do know is that women are less likely to receive doctorates in STEM fields and when they do they are less likely to receive tenure positions and tend to make lower salaries $[5,6,8]$. Theories abound as to why women are less likely to persist in STEM fields including a chilly climate [8-14], a lack of critical mass of women [15,16], and conflicts between family and work life [17]. However, many questions still remain unanswered as to why existing educational supports are not sufficient. Therefore this study will take a step beyond the existing educational research and examine physicists' perceptions of the impact of graduate school on their life outside of school and subsequent career choice through interviews.

Examination of descriptive themes and variables could provide a better empirical understanding of the process and interaction of females within physics doctorate programs. Without a more thorough understanding of why and how women make career choices based on aspects both inside and outside of school and their subsequent interaction, we cannot help them succeed and persist within STEM fields. This understanding could then further inquiry and evidence to impact public policy and educational practices and promote ways to strengthen advanced education and career opportunities for women in physics.

\section{RESEARCH QUESTIONS}

1A. What do female physics graduate students and professional Ph.D.s report about the impact of graduate school on their lives outside of graduate school? 
1B. How do their lives outside of school impact their perceptions of their career choice?

$2 \mathrm{~A}$. What do female physics graduate students and professional Ph.D.s report about their support system outside of school and its impact on their graduate school success?

2B. How does their support system outside of school impact their perception of their career choice?

\section{DATA AND METHODS}

\section{A. Data}

The data used in this paper were gathered as a part of Project Crossover, funded by the National Science Foundation and led by the second author. The first author coded the data and developed the data analysis, results, and conclusions for this study. Project Crossover is a sequential mixed methodological study designed to examine the transition from graduate student to independent researcher in chemistry and physics. The first phase of the study generated hypotheses through interviews with physical scientists who have experienced or are currently experiencing the science career progression from graduate student to independent researcher. The interview component of Project Crossover involved the collection of 125 interviews that were tape recorded. The interviews were semistructured and open ended. Conversations flowed smoothly with sharing of both the interviewee and the interviewer regarding physical science advanced education and experiences. The interviewees included graduate students, postdoctoral fellows, industrial scientists, and tenured faculty including two past Nobel Prize winners in physics and chemistry. Interviews also included some individuals who had previously been involved in physics or chemistry, but had since left science altogether. The main purpose of these interviews was to develop hypotheses linking graduate school experiences with career development among physical scientists. The duration of the interviews ranged from 30 minutes to 2.5 hours in length. Audio recordings were transcribed for analysis. In addition, no incentive was provided to the interviewees within the study other than the opportunity to provide dialogue about their experiences within physical science Ph.D.s.

\section{B. Sample}

This study consists of an analysis of eleven semistructured and open-ended interviews of female physical scientists from the Project Crossover data set. This sample is homogenous in that all of these women were in the process of receiving, or had received, doctorates in the field of physics. In particular, this data set included eight doctoral students that ranged from their first to fifth years within their respective physics programs, one doctoral fellow, one assistant professor, and one senior researcher. Pseudonyms were developed for the sample and listed with their current career stage and years at their current career stage in Table I.
TABLE I. Sample demographics including pseudonym, career stage, and years at current career stage.

\begin{tabular}{lcc}
\hline \hline Pseudonym & $\begin{array}{c}\text { Demographics } \\
\text { Title }\end{array}$ & Years \\
\hline Jane & Doctoral student & 1 \\
Vanessa & Doctoral student & 1 \\
Frances & Doctoral student & 2 \\
Elizabeth & Doctoral student & 2 \\
Sarah & Doctoral student & 3 \\
Debbie & Doctoral student & 4 \\
Kathy & Doctoral student & 5 \\
Laura & Doctoral student & 5 \\
Jenn & Doctoral fellow & 1 \\
Dorothy & Assistant professor & 6 \\
Jessica & Senior researcher & 9 \\
\hline \hline
\end{tabular}

Confidentiality agreements were signed that the race of participants would not be revealed in the sample and that pseudonyms would be used, as the field of female physics doctorates is so sparse that any indication of race may also clearly link a participant to their current personal and professional life. Because of the confidentiality protocol participants were not asked to identify their race or ethnicity over the phone-held interviews.

\section{Methodological overview}

Interviews were examined of female physicists in order to further understand perceptions and the decision making process regarding how these individuals constructed their realities about their career choice and their experiences outside of school. Career choice and academic pursuits is a phenomenon of individuals based on an interaction among personal, behavioral, and environmental variables [18]. A postpositivist paradigm provided scaffolding for the research by examining human knowledge and belief of personal experiences of the interviewees and their experiences within advanced physics programs.

\section{Data coding and analysis}

As noted earlier, the first author coded the data and developed the data analysis, results, and conclusions for this study. The interview data were collected prior to this study and are examined from a critical realist perspective, in that there are truths that can be examined through methods of cause and effect $[19,20]$. However, because these methods are so intricate they cannot be truly understood through quantitative methods alone [19,20]. Literature on career choice and persistence [18] indicates how complicated this process is without the added examination of gender within STEM fields [5-8]. Therefore, Miles and Huberman's [20] approach focuses on generalizability and aggregating the data in order to find themes within the material regarding the research questions above. Epistemological understandings indicate that these themes 
can be examined based on both existing literature and the interviewee's responses [20]. Based on this approach, the research began with a code list prior to data analysis of the interviews. This was a means to help further aggregate and decipher the themes within the data. A brief literature review indicated that preliminary codes of interest included academic [3], nonacademic [3], teaching, research [3], industry or government [3], expectations [3], preferences [3], aspirations [7], behavior [18], personal [18], and environmental [18]. Further expansion of this preliminary code list is listed in the index of this paper (see Appendix A, Table II).

Each interview was individually read multiple times and coded by the first author using these categories and further emergent codes that were developed throughout the analysis process leading to a final blended coding approach. Coding was cyclical and went through multiple processes in order to fully aggregate the data and discover all of the themes. A list of the final complete set of codes used in the data analysis is listed in the index of this paper as well (see Appendix A, Table III). Data were reduced through methods of summaries, coding, and "memoing," and the development of data displays. Coding, data aggregation, and data displays were created and completed with the use of NVivo9 to examine the phenomenon of female physicists and their professional and personal experiences and subsequent interaction while obtaining a Ph.D. After the data were coded, sets of attributes were created that allowed the examination of any relationships that may exist between certain subgroups of the interview population. The attributes included married, boyfriend, single, professor, student, and fellow. These attributes were determined through the coding process of the data analysis. However, it is important to note that this information was not available for all of the participants as the interviews were semistructured and open ended. Based on the available attributes, a series of matrices were created in order to explore the codes by the interviewees' specific relationship type and career timeline attributes. It was the first author's hypothesis that the specific subgroups would not differ greatly.

Finally, the first author remembered her role as a female, Caucasian, and education doctoral candidate in this study and how it may influence the analysis through intensive memoing, reflexive journaling, and analytic notes. In addition, she kept in mind the advantages of using NVivo9 analytic software to assist in the data aggregation and display process while still maintaining mindfulness about potential disadvantages such as becoming too removed from the actual interviews and preventing any data loss. Furthermore, the first author participated in workshops and received feedback with fellow research group members. In order to maintain the critical realist Miles and Huberman and emergent coding approach, the findings will be presented by theme-based questions rather than focusing on individual groups or interviews within this paper.

\section{RESULTS}

\section{A. What do female physics graduate students and professional Ph.D.s report about the impact of graduate school on their lives outside of graduate school?}

In analyzing the interview data there were many themes that emerged regarding the influence of graduate school on female physics students' lives outside of school. However, it is important to note that it was discovered that this influence was not unidirectional but that feelings towards graduate school were also influenced by outside activities as well. Here ten out of eleven interviewees either responded or spoke on their own accord about the impact of graduate school on their life outside of school and vice versa. The themes that emerged included guilt, a feeling of hindered progress, inadequate peer social skills, support from one's department, as well as a repeated need and search for life balance (see Appendix B, Fig. 1).

\section{Guilt and hindered progress}

Five of the female physicists specifically spoke of guilt regarding having a life outside of graduate school. This theme or code often went hand in hand, as referenced by four of the interviewees, with the feeling that these outside activities hindered their progress within graduate school. As one female doctoral student, Frances, said she avoided activities outside of school, "because I wasn't enjoying it. Like even if I would go out I was feeling guilty." Students that intentionally set aside time outside of school to spend with their family or friends often felt this time away from work would hinder their progress. Another graduate student, Elizabeth, who took time away from work to spend with her husband stated, "So it's in one way like its emotional support and in the other way it's less time available for work.... But other students who can do that (work without interruption) get ahead a little bit faster." Two of the interviewees out of eleven stated that their marriage negatively impacted their work. Overall four out of eleven physicists reported being married. This conflict between family life and work life has been well cited within literature [17].

\section{Peer social skills}

Beyond family support, two of the female physicists also spoke of the lack of peer social skills and gender issues in their department as being both a hindrance within the workplace and outside of it in forming a social network. Gardner's [4] research on female science Ph.D.s showed that they expressed a predominate feeling of not fitting in during the socialization process and believed it was due to being underrepresented, as well as gender issues. As one interviewee, Dorothy, currently an assistant professor, stated about her peers, "Maybe they were geniuses in their own way. They certainly didn't have the best social skills.... And I would say there was a little bit of that attitude that, oh, you're a woman, why are you here?" Negative departmental relationships with peers were stressed as being isolating both within and outside of 
work. Furthermore, one sees that the stress with fellow graduate students also included a perceived gender bias, where Dorothy felt as though the students were less approachable because she was a woman and therefore a minority within her department. Females in as early as high school physics course work have reported this gender bias and isolation [21]. Research has shown that female selfconfidence tends to diminish with greater levels of physics education regardless of their success in relation to their peers $[22,23]$. Peer social skills play a part in this experience, as females may be more likely to question their abilities and leave the field of physics due to negative social experiences that prevent the formation of a supportive social network.

\section{Departmental support}

Research studies have shown that forming a critical mass of underrepresented populations, such as women within physics departments, encourages women to enter and persist within programs [24,25]. Beyond that, Whitten, Foster, and Duncombe's [26] research points toward the use of creating a supportive department culture in order to help female physicists persist in the field. Two interviewees stated that departmental or advisor support can have either a substantial positive or negative impact upon work-life balance and participation in activities outside of school. One graduate student, Elizabeth, stated that her advisor was both beneficial in helping her professional success while also being detrimental to her current lifestyle by being overworked. As Elizabeth stated, "because certainly he's paving the way for me to have a good future career. But I don't know if he's paving the way for me to like you know survive in the present." Another new graduate student, Jane, spoke of the ideal hypothetical advisor that would help provide balance between her school and home life. She said that,

I also need someone who's not going to let me get away with being lazy.... And I wouldn't want someone who is really hard on me and that would expect a lot of me and so would push me really hard. Now I'm like, maybe there's more to life than work. So maybe my attitude's changed a little bit.

It is important to note that these doctoral students and professionals felt that work-life balance could be supported through an advisor, mentor, peer, or an administrator in their academic departments. Interestingly, none of the students spoke of female graduate advisors; those interviewees that spoke of their advisors described them as being males.

\section{School balance}

Overall ten out of eleven of the female physicists talked about this repeated need for balance as a graduate student. These females referred to it almost always as something they were trying to attain, but was just outside of their reach. One graduate student, Kathy, described the beginning of her graduate program and the stress it caused in her life by stating, "it was like morning, noon, night, holidays. It was like I had no life. And the only life I had was because I lived with Frank, so my partner was at home." Tying back into the theme of guilt, Frances spoke of how guilt previously prevented her from creating balance within her life. She stated,

(I)f you don't give that time to yourself it's just it's never going to appear and no one's going to tell you like to take a holiday or to take a break. But I've just recently in the past few months given myself that way to have a break and to have a life and to not feel guilty about having other interests that for the first two years I just had these butterflies in my stomach and just constantly feeling like I had to prove myself or that I wasn't good enough and that I wasn't working hard enough and so that was not letting me even enjoy the things I was doing outside of this.

Repeatedly this theme of balance came up within the interviews, either directly or indirectly. As mentioned above, certain factors within graduate school led to more ease and less feeling of guilt or inadequacy when maintaining a life outside of school such as strong peer role models and departmental support. One interviewee, Dorothy, spoke of the ideal lifestyle that was not reflected by female academics at the university,

Well, balance with research and a little bit of teaching, $a$ little bit of mentoring, or even a little bit of a personal life in the sense that we-I'm thinking specifically of a couple of female faculty members at (my university). They're great researchers, and I can't say how they are as teachers because I didn't have them, but as mentors and as role models, they were a little scary.... Very intense. Very driven. Very aggressive...they did not seem to be the most content, happy, calm people in the world.

It is important to also reflect on how one female physicist views other females in the career that she was about to enter. So it appears that the cultural influences within a school often painted these students' obtainment of balance and a less stressful lifestyle. Dorothy later reflects on the importance of this support by saying, "So, there were no problems there in terms of equipment, money, and going to conferences. That was also available. I think the most significant thing probably was the personal and emotional support." Support, specifically the number of supportive female faculty within a department, is critical to female success within physics [27]. This departmental support, or lack thereof, ties nicely into what experiences outside of the department and graduate school help females be successful and confident in their career choices as physicists. 


\section{B. How do their lives outside of school impact their perceptions of their career choice?}

Seven out of eleven of the participants talked about how their lives outside of graduate school colored the perception of their career choice. The four main themes that emerged through coding included a perceived lack of time outside of school, lack of time for family, the need for support, and further reflection on the importance of a balance between one's life and their career (see Appendix B, Fig. 2).

\section{Lack of time outside of school}

Interviewees frequently spoke with concern of a perceived lack of time outside of school as possibly extending into their future careers. Three of the females interviewed described this lack of time outside of school and work indepth. For example, Frances spoke of how she sometimes thinks of leaving graduate school in order to have more time outside of school. She stated,

I have had this thought in the back of my head like what am I doing why do not I just go and start my life. Things like that. So for me it would just be tired of being in school. Tired of like um feeling I have to prove myself all the time or tired-you know things like that and just wanting to get some pleasure out of life or also being able to actually read something other than physics or learn about like being interested in other things. Like I feel like you have to put a lot of that aside.

Hodgson, Scanlon, and Whitelegg [28] show that females often feel that they must make some sort of compromise in their personal lives in order to be successful within the field of physics.

\section{Lack of time for family}

Interestingly, when the female physicists talked about a lack of time for family, they never spoke in reference to their own personal wishes to have children. Specifically three out of eleven of the physicists discussed a lack of time for their family, but not children, being a concern for their future career route. However, when they mentioned children they were speaking in regard to role models in the department or why they think someone else may leave a career within physics. For example, Jane said the following about a professor in her department, "I talked to Bob; he seems like the most balanced person out there and he says, 'I see my kids every two weeks.' Yeah. He's like, 'Yeah, I always feel like I'm not doing enough."' The only interviewee, Kathy, who spoke in regard to personally having children, said the following about her future career,

Well, I think that if I had planned on having children then yes, I would see there being some conflict with that.
But I had never planned on ever having children, so I do not think I have to sacrifice anything. It may be hard for me to walk my dog three times a day when I get one.

Prior research has shown that female scientists report that one of the biggest challenges to remaining within the field is creating a balance between work and family [29]. A fundamental difference in the responses to this research question was this lack of an expressed interest of having children of their own or worrying about an impending "biological clock." As Kathy states, this lack of concern towards children has encouraged her to proceed within a career that may not be considered family friendly.

\section{Support}

While having children may not have been an expressed necessity, support was. An assistant professor, Dorothy, spoke of how external support is very important in order to be successful as a scientist, especially as a female. Dorothy stated, "And just having other people, whether or not they're the same race, the same gender, just whoever you can find that is there to support, that helps a lot." While this theme of support was not as expressed as within the first research question, it is important to show how it tied into this research theme as well.

\section{Career balance}

In the end, the senior researcher, assistant professor, doctoral fellow, and doctoral students focused on a need for balance in their future careers. This was an overarching theme in seven out of eleven of the females interviewed. While this does connect to the first research question about graduate school experiences, it also is pertinent to this question as it clearly impacted their desired career choice. Four of the students interviewed expressed a clear preference not to be placed in a work position similar to their graduate school experience. Three of these students said they would rather go to a university where they could teach more and do research less, whereas one of the students said they would rather work for the government so they could have more free time. Historically, research has shown that women are less likely to make use of their research science qualifications and more likely to be overqualified in their employment and to enter areas such as teaching $[29,30]$.

\section{A. What do female physical science graduate students and professional Ph.D.s report about their support system outside of school and its impact on their graduate school success?}

Similar to other research work done on female physicists [28], little mention of mentors or advisors was discussed as a part of their external support system. Data were further analyzed and coded for interviewee reports on their support systems outside of school. Overall, nine out of eleven of the females interviewed said a support system was 
essential to their success as a graduate student. However, interestingly their forms of support varied and included parents, relationships, department, and friends (see Appendix B, Fig. 3). The majority of female physicists reported that without these relationships they would not have persisted or been as successful in their graduate program.

\section{Parents}

Specifically five out of eleven females recount that their parents provided support leading to their graduate school success. This result is consistent with research literature that shows that general precollege parental support is a critical factor in female persistence within the sciences $[31,32]$. Parental support in this study specifically included such things as lifestyle advice, general parent advice, close proximity to home, and early support in their career interests. Overall one out of eleven participants reported lifestyle advice, three out of eleven participants reported general parent advice, three out of eleven participants reported close proximity to home, and one participant reported early support in their interests as being important to their graduate school success. For example, Debbie stated the following about her parents, "My mom has a master's. My dad taught in the schools for a while. So they're very big on education and pretty liberal in terms of you can do anything, which I think was a big part of it." This strand of parental support shows up later in regard to career support in this study as well.

\section{Relationships}

Fewer participants reported a relationship as being important to their graduate school success. Prior research has shown that being in a relationship can both help and hinder a career within the field of science [17]. Only four out of eleven participants reported that a relationship or marriage helped them persist within their programs. Overall, four participants reported being married, one participant reported being engaged, and one participant reported being in a relationship out of eleven female physicists in this sample. In addition, these relationships often filtered their impression of their graduate school program, and as mentioned later their perception of their future career choice. One graduate student, Debbie, that was married said, "It's nice to have someone to go home to who is there when I really need it and who's willing to pick up the slack when I'm really stressed." However, the majority of students, five out of eleven, were not in committed relationships and had to find support elsewhere.

\section{Department}

The greatest amount of respondents, nine out of eleven, stated that some form of university support that was provided outside of the traditional doctorate program helped them be successful as a graduate student. Included within these numbers were two physicists that said it was an administrator, five physicists reported fellow graduate students, and two physicists reported that specific women's groups helped them persist within their graduate school programs, through providing external support. Jane stated that her physics women's group was "so helpful, just in terms of everything. Like they've really gone out of their way to look out for us." As this was the largest group of respondents, it is important to keep in mind that universities can provide support to their female physics Ph.D.s in a myriad of ways externally by providing them with a strong support system. This departmental support has been shown to be critical in order to prevent feelings of isolation and encourage female persistence in the sciences [28].

\section{Friends}

Finally, two out of eleven of the females reported that their friends were an important influence on their success within their graduate school programs. These friends were described as providing them perspective and living within close proximity to the school that they attended.

\section{B. How does their support system outside of school impact their perception of their career choice?}

Oftentimes this external support system colored students' perceptions of their future career choice in many ways. Seven out of eleven of the participants described how their support system influenced their career choice and persistence. All of these answers included some form of parental or family support through early encouragement within science and mathematics (see Appendix B, Fig. 4). As one participant, Frances, said, "Ah yes. Like it was kind of just assumed that (I see) laugh we were going to go into science."

In addition, all of the participants spoke of a shared interest in science and or mathematics by another family member, particularly parents. As Jessica stated, "Well, my father's a physicist. My brother was studying physics. He's a year ahead of me. My mother has a degree in engineering physics.... So it was a natural thing to do." Even more interesting, was that this parental interest was shared with their children early whether it was through books, clubs, hobbies, or movies. As Elizabeth said, "Yeah both my parents have been Star Trek fans for a long time, my dad's an engineer and my mom and dad both value education a lot so as soon as I started to show any propensity in science both of my parents were like, 'Oh you're going to have a Ph.D. You're going to do science.'" Furthermore, Elizabeth points out the early encouragement of these interests by saying that they started, "(p)robably when I was about ten or twelve. They would get me subscriptions to (science) magazines." Regardless of the activity, this theme of a science identity was very prevalent throughout seven of the interviews of these female physicists. Carlone and Johnson [33] have shown that early development and sustained identity development as a research scientist leads to a greater persistence within the field of physics. In addition, seminal work has shown that students who expressed interest early in science and participated in unstructured activities are more likely to remain within the field [34-36]. 
Here the reflection on parents playing an intrinsic role in this early interest and persistence is of relevance to out-ofschool time activities. This was something that was often mentioned in their interviews of their own accord as being the most important thing that led them toward their eventual career choice. Parental support in this identity development is what they continue to reflect upon during their graduate school career, or in their profession, as being extremely relevant and essential to their commitment toward their field of study.

\section{CONCLUSION}

Overall the results from this paper were developed through Miles and Huberman's [20] approach and emergent coding methods in order to aggregate the data to tease out the graduate school and personal life processes of females in the field of physics. It is important to note that matrices were examined for all the results based on the relationship and career timeline attributes and no specific differences emerged based on these results. When the research questions were combined together, a very interesting model of female physics graduate school and career choice developed (see Appendix B, Fig. 5). This overall model and further emergent codes across questions that could be studied (e.g., selfconfidence, perceptions of women within the field, and science identity) is beyond the scope of one paper, but specific results should be examined. The results indicate that female physicists experience conflict in achieving balance within their graduate school experiences and personal lives and that this then influences their view of their future careers and possible career choices. These females individually reported that graduate school often causes feelings of guilt and that maintaining a life outside of graduate school can lead to a feeling of hindered progress. In addition, inadequate peer social skills negatively impacted many of the females, whereas support from their department helped assist with this work-life conflict. In the end, this repeated need and search for balance in their lives transfers to their future concerns within their careers. Reported concerns with their current graduate school experience, which may influence their future careers, included a perceived lack of time outside of school, lack of time for family, a need for support, and further reflection on the importance of a balance between one's life and their career. Interestingly, the combination of these factors influenced four of the women to indicate that they would rather have a career more based on teaching or working for the government, in order to maintain a better work-life balance. Unfortunately it is feelings like this that often contribute to the lack of females within tenured physics academic positions $[5,6,8]$.

What we do know is that there are certain supports that helped these females to persist within their fields as well as enter and follow the career paths that they chose. While their graduate school support systems varied greatly and included parents, relationships, department factors, and friends. These support systems were what these females reported helped them persist within their fields. Even more intriguing was that the majority of females talked about how they were influenced to enter the career through early encouragement, support, hobbies, and shared interests with their parents and family. These results mirror prior research indicating the importance of early interest in science and participation in unstructured activities in science [34-37]. A greater focus on informal and out-of-school science activities for females that incorporate family activities early in life may help influence their entrance into a physics career later in life. While these informal activities occurred within the home, they are not beyond the influence of education and public policy [37]. These females' accounts provide support for the work that is being done within informal science programs and science education. Public science programs may help develop these early interests and provide family participation in informal science activities where females may not have access to this early support and experience [37].

Further policy indications from this paper include a reflection on what can be influenced to get females into the field of physics and to help them endure graduate school and persist into a future career. A primary focus is the need for departmental support whether it is through advisors, mentors, peers, or women's support groups [28]. These factors were all listed as being instrumental in these females' graduate school success. Universities can better prepare their female doctoral students by developing a network of advisors, mentors, and administrators that address and model the ability to obtain a balance between their career and home life. Participants described that these individuals often helped prepare them to be successful professionally but not personally in regard to their doctoral careers in physics. By training departmental support staff to help females with these work-life issues [29], we may be better able to support women within these academic positions. Additional policy indications include providing an indirect support system through peers and support groups for these females. While women are often underrepresented in these programs, peer socialization and workshop activities can be developed to encourage the inclusion of women into these physics programs and departments as future faculty members. Finally, women support groups can be developed across university STEM based departments thereby providing female physicists a social network and critical mass of peers both within and outside of the university.

\section{LIMITATIONS AND FUTURE RESEARCH}

Possible limitations within the examination of the interviews include the fact that they were completed prior to the analysis. Because of this there is no room for clarification regarding any remaining inherent questions within the data. Furthermore, the data were analyzed based on themes that were not always directly asked within the interviews 
due to the semistructured and open-ended basis of the interviews. Therefore numbers within the results purely reflect the information that the interviewees chose to share with the interviewer throughout the interviews. In addition, the data are limited to the transcribed interviews so there are no additional artifacts such as Emails, letters, or so on to work in the data aggregation. Finally, the data are provided from the sole positionality of the interviewee and so data results will provide only one viewpoint of the experience of the subjects within their experiences.

There are many factors that go into the development and success of women within the field of physics. Specific to this research study these female physicists reported both the early and long-term support outside of school by family, and later support in one's department, as being very important to their persistence within the field. Further work still needs to be done to increase female representation within the field of physics. Future research implications include the need to examine emergent codes that were found within the analysis for this paper and yet beyond the scope of this paper. These codes included an examination of female self-confidence, perceptions of women within the field, and science identity. Research should examine what type of informal science and departmental programs are most beneficial for female physicists. A better understanding of female experience within these programs and their personal identity can help bolster public policy and the field of physics.

\section{ACKNOWLEDGMENTS}

Support was received from the National Science Foundation (NSF DRL 1010935, NSF REC 0440002) and the Robert N. Noyce Foundation.

\section{APPENDIX A: CODING LISTS}

Coding lists include a preliminary code list developed from existing literature and a final code list developed through a blended coding approach of both preliminary and emergent codes.

TABLE II. Preliminary code list based on existing literature. This was a means to help further aggregate and decipher the themes within the data.

\begin{tabular}{|c|c|}
\hline Career choice & $\mathrm{CC}$ \\
\hline CC: Academic & CC-ACD \\
\hline CC: Nonacademic & CC-NONACD \\
\hline CC: Teaching & CC-TEA \\
\hline CC: Research & CC-RES \\
\hline $\mathrm{CC}$ : Industry/government & CC-IND/GOV \\
\hline CC: Advisor & CC-ADV \\
\hline CC: Research group & CC-RG \\
\hline School & $\mathrm{SC}$ \\
\hline SC: Expectations & SC-EXP \\
\hline SC: Preferences & SC-PREF \\
\hline SC: Behavior & SC-BEH \\
\hline SC: Personal & SC-PER \\
\hline SC: Environmental & SC-ENV \\
\hline SC: Marriage & SC-MAR \\
\hline SC: Children & $\mathrm{SC}-\mathrm{CH}$ \\
\hline SC: Advisor & SC-ADV \\
\hline SC: Research group & SC-RG \\
\hline SC: Aspirations & SC-ASP \\
\hline Outside of school & OS \\
\hline OS: Expectations & OS-EXP \\
\hline OS: Preferences & OS-PREF \\
\hline OS: Behavior & OS-BEH \\
\hline OS: Personal & OS-PER \\
\hline OS: Environmental & OS-ENV \\
\hline OS: Marriage & OS-MAR \\
\hline OS: Children & $\mathrm{OS}-\mathrm{CH}$ \\
\hline OS: Advisor & OS-ADV \\
\hline OS: Research group & OS-RG \\
\hline OS: Aspirations & OS-ASP \\
\hline
\end{tabular}

TABLE III. Final code list developed through a blended coding approach of preliminary and emergent codes.

\begin{tabular}{ll}
\hline \hline Career choice & CC \\
\hline CC: Lack of life & CC-LOL \\
CC: Lack of time for family & CC-LOTF \\
CC: Support & CC-SUPP \\
CC: Balance career & CC-BALC \\
CC: Early encouragement & CC-EARLE \\
CC: Parental support & CC-PARSU \\
School & SC \\
SC: Guilt & SC-GUI \\
SC: Hinders progress & SC-HINPR \\
SC: Peers social skills & SC-PESS \\
SC: Department support & SC-DEPS \\
SC: Need balance & SC-NEBA \\
SC: Lifestyle advice & SC-LIFAD \\
SC: Perspective & SC-PERS \\
SC: Lack of support & SC-LACS \\
Outside of school & OS \\
OS: Guilt & OS-GUI \\
OS: Hinders progress & OS-HINPR \\
OS: Peers social skills & OS-PESS \\
OS: Department support & OS-DEPS \\
OS: Need balance & OS-NEDBA \\
OS: Lack of life & OS-LOL \\
OS: Lack of time for family & OS-LOTF \\
OS: Support & OS-SUPP \\
OS: Balance career & OS-BALC \\
OS: Lifestyle advice & OS-LIFAD \\
OS: Perspective & OS-PERS \\
OS: Lack of support & OS-LACS \\
OS: Early encouragement & OS-EARLE \\
OS: Parental support & OS-PARSU \\
\hline \hline
\end{tabular}




\section{APPENDIX B: MODELS}

Findings are presented as models by theme-based research questions in order to maintain a critical realist and emergent coding approach. Please note that this information was not available for all of the participants as the interviews were semistructured and open ended.

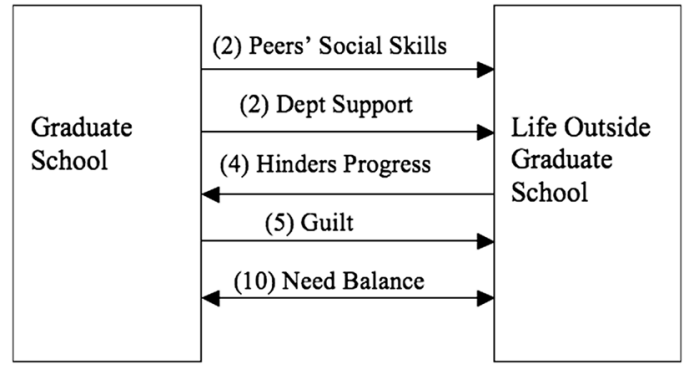

FIG. 1. Female voluntary qualitative response rate to question 1A. What do female physics graduate students and professional Ph.D.s report about the impact of graduate school on their lives outside of graduate school?

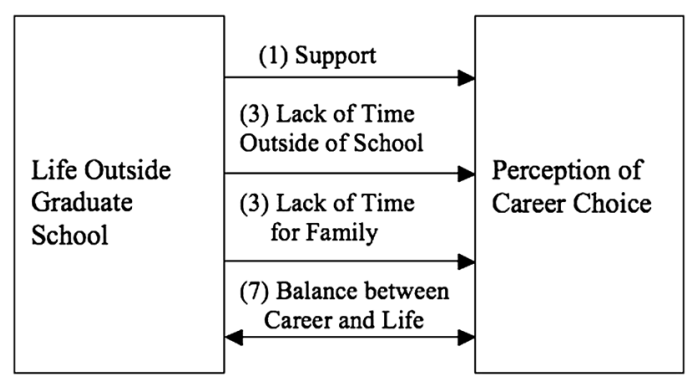

FIG. 2. 1B. How do their lives outside of school impact their perception of their career choice?

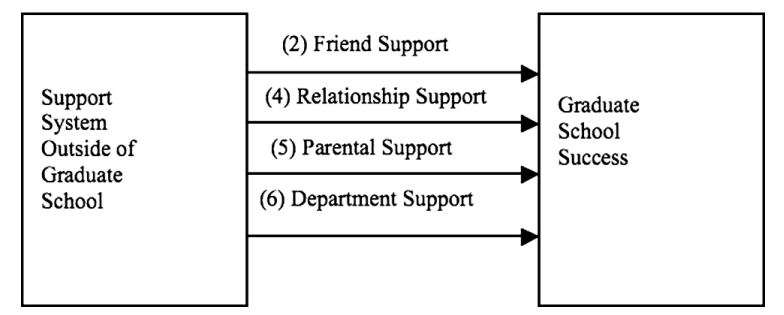

FIG. 3. 2A. What do female physics graduate students and professional Ph.D.s report about their support system outside of school and its impact on their graduate school success?

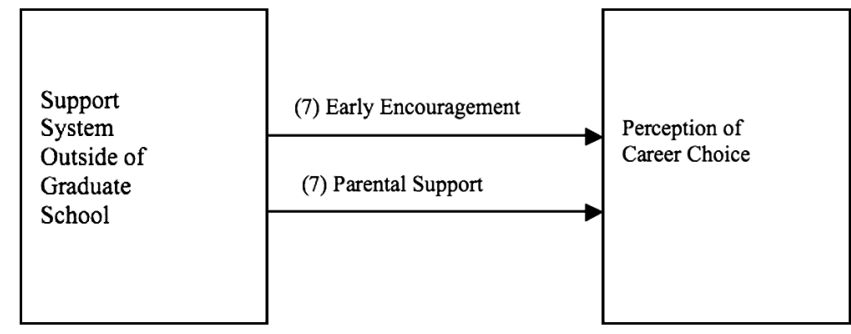

FIG. 4. 2B. How does their support system outside of school impact their perception of their career choice?

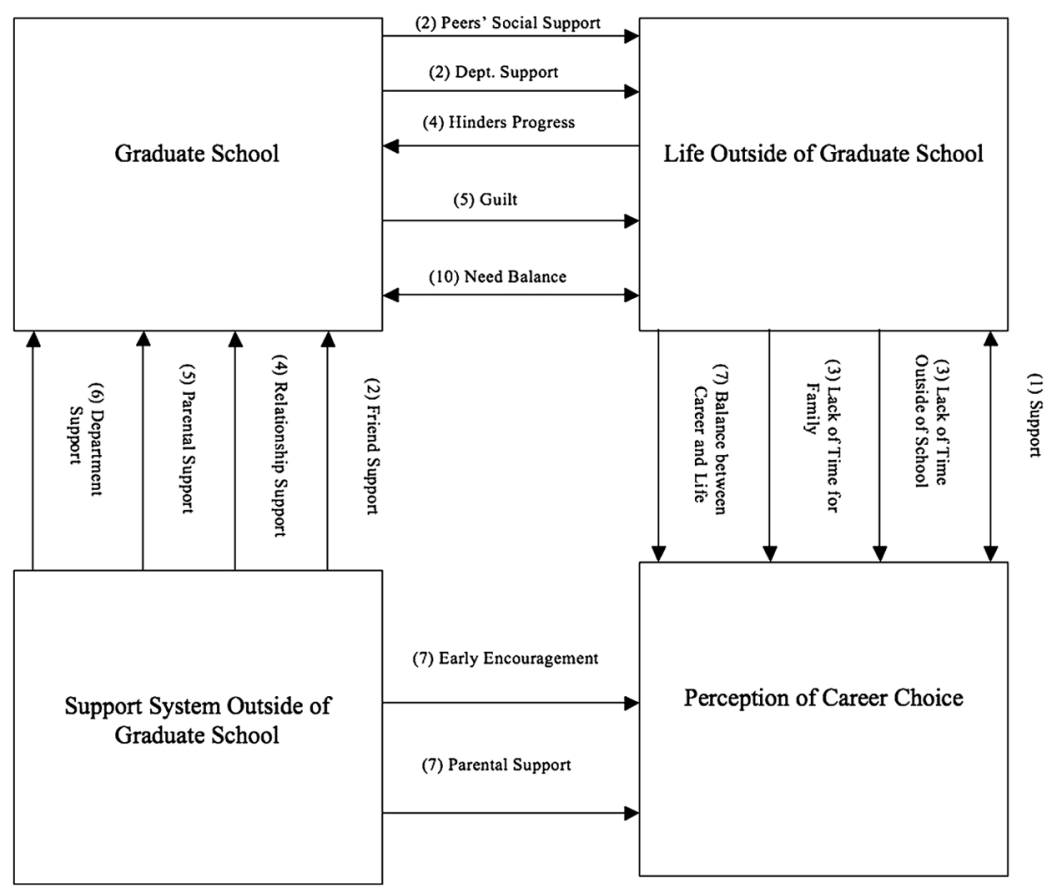

FIG. 5. Final model. 
[1] Committee on Prospering in the Global Economy of the 21st Century: An Agenda for American Science and Technology, Rising Above the Gathering Storm: Energizing and Employing America for a Brighter Economic Future (National Academies Press, Washington, DC, 2007).

[2] Committee on Prospering in the Global Economy of the 21st Century: An Agenda for American Science and Technology, Rising Above the Gathering Storm, Revisted: Rapidly Approaching Category 5 (National Academies Press, Washington, DC, 2010).

[3] M.F. Fox and P.E. Stephan, Careers of young scientists: Preferences, prospects and realities by gender and field, Soc. Stud. Sci. 31, 109 (2001).

[4] S. K. Gardner, Fitting the mold of graduate school: A qualitative study of socialization in doctoral education, Innovative Higher Educ. 33, 125 (2008).

[5] C. Hill, C. Corbett, and A. St. Rose, Why so Few? Women in Science, Technology, Engineering, and Mathematics (AAUW, Washington, DC, 2010), http://www.aauw.org/ files/2013/02/Why-So-Few-Women-in-Science-TechnologyEngineering-and-Mathematics.pdf.

[6] National Center for Science and Engineering Statistics: Data Tables, National Science Foundation, 2010, http://www.nsf .gov/statistics/nsf09317/content.cfm?pub_id=3920\&id=2.

[7] M. M. Nauta, D. L. Epperson, and J. H. Kahn, A multiplegroups analysis of predictors of higher level career aspirations among women in mathematics, science, and engineering majors?, J. Counsel. Psychol. 45, 483 (1998).

[8] S. Acker and G. Feuerverger, Doing good and feeling bad: the work of women university teachers, Cambridge J. Educ. 26, 401 (1996).

[9] B. Barres, Does gender matter?, Nature (London) 442, 133 (2006).

[10] M. Ferreira, The research lab: A chilly place for graduate women, J. Women Minorities Sci. Eng. 8, 85 (2002).

[11] R. Gunter and A. Stambach, Differences in men and women scientists' perceptions of workplace climate, J. Women Minorities Sci. Eng. 11, 97 (2005).

[12] R. J. Menges and W.H. Exum, Barriers to the progress of women and minority faculty, J. Higher Educ. 54, 123 (1983).

[13] S. Prentice, The conceptual politics of chilly climate controversies, Gender Educ. 12, 195 (2000).

[14] I. H. Settles, L. M. Cortina, J. Malley, and A. J. Stewart, The climate for women in academic science: The good, the bad, and the changeable, Psychol. Women Q. 30, 47 (2006).

[15] J. Girves and V. Wemmerus, Developing models of graduate student degree progress, J. Higher Educ. 59, 163 (1988).

[16] S. Kleinman, Women in science and engineering building community online, J. Women Minorities Sci. Eng. 9, 73 (2003).

[17] V. L. Wyss and R. H. Tai, Conflicts between graduate study in science and family life, Coll. Stud. J. 44, 475 (2010).

[18] R. W. Lent, A social cognitive view of career development and counseling, in Career Development and Counseling: Putting Theory and Research to Work, edited by S. D. Brown and R.W. Lent (Wiley, New York, 2000), pp. 101-127.
[19] K. J. Doubet, Teacher fidelity and student response to a model of differentiation as implemented in one high school, Ph.D. dissertation, University of Virginia, 2007.

[20] M. B. Miles and A.M. Huberman, Qualitative Data Analysis (Sage Publications, Inc., Thousand Oaks, CA, 1994), 2nd ed.

[21] F. McDonnell, Why so few choose physics: An alternative explanation for the leaky pipeline, Am. J. Phys. 73, 583 (2005).

[22] P. Haussler and L. Hoffmann, An intervention study to enhance girls' interest, self-concept and achievement in physics classes, J. Res. Sci. Teach. 39, 870 (2002).

[23] T. DeBacker and R. Nelson, Motivation to learn science: differences related to gender, class type, and ability, J. Educ. Res. 93, 245 (2000).

[24] E. M. Ellis, The impact of race and gender on graduate school socialization, satisfaction with doctoral study, and commitment to degree completion, West. J. Black Stud. 25, 30 (2001).

[25] C.S. V. Turner, Diversifying the Faculty: A Guidebook for Search Committees (Association of American Colleges and Universities, Washington, DC, 2002).

[26] B. L. Whitten, S. R. Foster, and M. L. Duncombe, What works for women in undergraduate physics?, Phys. Today 56, No. 9, 46 (2003).

[27] M.E. Tidball, Baccalaureate origins of natural science doctorates, J. Higher Educ. 57, 606 (1986).

[28] B. Hodgson, E. Scanlon, and E. Whitelegg, Barriers and constraints: Women physicists perceptions of career progress, Phys. Educ. 35, 454 (2000).

[29] S. V. Rosser and E. O. Lane, Key barriers for academic institutions seeking to retain female scientists and engineers: Family-unfriendly policies, low numbers, stereotypes, and harassment, J. Women Minorities Sci. Eng. 8, 161 (2002).

[30] J. Fielding and J. Glover, Women and science graduates in Britain: The value of secondary analysis of large scale data sets, Work Employ. Soc. 13, 353 (1999).

[31] S.W. Brown, Hispanic students majoring in science or engineering: What happened in their educational journeys?, J. Women Minorities Sci. Eng. 8, 123 (2002).

[32] M. L. Russell and M. M. Atwater, Traveling the road to success: A discourse on persistence throughout the science pipeline with African American students at a predominantly white institution, J. Res. Sci. Teach. 42, 691 (2005).

[33] H. B. Carlone and A. Johnson, Understanding the science experiences of successful women of color: Science identity as an analytic lens, J. Res. Sci. Teach. 44, 1187 (2007).

[34] A. V. Maltese and R.H. Tai, Eyeballs in the fridge: Sources of early interest in science, Int. J. Sci. Educ. 32, 669 (2010).

[35] G. L. Nazier, Science and engineering professors: Why did they choose science as a career?, School Sci. Math. 93, 321 (1993).

[36] R. H. Tai, C. Q. Liu, A. V. Maltese, and X. Fan, Planning early for careers in science, Science 312, 1143 (2006).

[37] K. P. Dabney, D. Chakraverty, and R. H. Tai, The association of family influence and initial interest in science, Sci. Educ. 97, 395 (2013). 